\title{
China's child policy shift and its impact on Shanghai and Hangzhou women's decision-making
}

This article was published in the following Dove Press journal:

International Journal of Women's Health

\author{
Simone Eliane Schwank ${ }^{1,2}$ \\ Chunyi $\mathrm{Gu}^{3,4}$ \\ Zhouli $\mathrm{Cao}^{5}$ \\ Ewa Andersson' \\ Hongli Jiang ${ }^{4}$ \\ Yan Ding ${ }^{3}$ \\ Helena Lindgren' \\ 'Karolinska Institutet, Women's and \\ Children's Health, Reproductive \\ Health, Solna, Sweden; ${ }^{2}$ Columbia \\ University, Center for Psychoanalytic \\ Training and Research, New York, \\ NY, USA; ${ }^{3}$ Nursing Department, \\ Fudan University, Obstetrics and \\ Gynecology Hospital, Shanghai, China; \\ ${ }^{4}$ School of Social Science, Hangzhou \\ Normal University, Qianjiang College, \\ Hangzhou, China; ${ }^{5}$ Department of \\ Health Economics, Fudan University, \\ School of Public Health, Shanghai, \\ China
}

Objectives: The Chinese government launched the two-child policy in 2015 to counteract the demographic changes, skewed sex ratio, and decreasing number of labor force. The policy shift has a significant impact on all levels of society and economy. This study aimed to describe how Mainland Chinese women face this new decision-making on their reproduction and family planning and captures factors contributing to the judgment and decision-making.

Method: The present qualitative study included a sample of 37 women, with an average age of 29.51 years, and well educated with bachelor degrees from urban areas of Shanghai and Hangzhou cities. The women were interviewed by social science students, using a 26 -item interview targeting the women's decision-making, expectations, and wishes with regard to the two-child policy.

Results: The contributors include the status of women, career, benefits, and challenges of two children, one-child generation, governmental support, and restrictions of reproductive freedom. These factors contribute to the women's prolonged decision-making on whether to have a second child. These factors highlight the impact of the policy on perinatal health, societal, and economic changes. The study illustrates the need to continue understanding the impact of the child policy shift for families and the society of the China on multiple levels.

Conclusion: With the outcomes of research on the families' judgment and decision-making with regard to a second child, support can be targeted where it is needed the most. The acquired knowledge may serve as a prognosis for the child policy's future development and used to target perinatal care and education of health care specialists, essential to governmental planning and resource allocation.

Keywords: Chinese child policy, perinatal health, reproduction, women, decision-making

\section{Introduction}

In 2015, China shifted from one-child policy introduced in 1979 to two-child policy. The policy shift is intended to countermeasure the demographic development of an aging population, skewed sex ratios, and a shrinking labor supply. ${ }^{1}$ The child policy shift has an immense impact on Chinese society, its families, especially women, the health care and education systems, as well as the economy of the China. ${ }^{2}$ The mechanisms the policy put into place are unique for the present time of change and bring the health care system and education under pressure to meet the new challenges. The detailed investigation of causes and effects of the policy are essential to target resources properly and prepare the different system and institutions to the change. The child policy shift will contribute to a change in the constitution of the Chinese society. Family norms considered standard are put into new perspectives and will change. This family structure shift from 4-2-1 to 4-2-2 will not only affect the individual, but also the society on a larger scale. ${ }^{3}$ The impact of the child policy shift is particularly influencing women's career and life choices, especially in urban cities such as Shanghai
Correspondence: Simone Eliane Schwank Karolinska Institute, Women's and Children's Health, Reproductive Health, Tomtebodavägen I8a, I7I 77 Stockholm, Sweden

Tel +46707999574

Email simone.schwank@ki.se 
and Hangzhou. ${ }^{2}$ The demand for more obstetric and perinatal care, as well as pediatric specialists, will increase. The onechild policy impacted the women's use of important obstetric care services, for example, an increased risk of mortality for women with unapproved pregnancies. ${ }^{4} \mathrm{Ni}$ and Rossignol ${ }^{5}$ further hypothesized that the economic and social penalties for noncompliance to the policy probably kept women from seeking the important obstetric care services that could contribute to reduce the increased risk of mortality for unapproved pregnancies. The effect of China's one-child policy on prenatal and obstetric care utilization will expectantly change and drive women to seek more perinatal care. ${ }^{5}$ The increase in obstetric care specialists, such as well-trained midwives, could contribute to meet the needs for more obstetric and perinatal health care specialists and services. ${ }^{6-8}$

A recent United Nations call, China Gender Fund for Research and Advocacy, focused on the impact of the two-child policy. It emphasized the need to understand the women's disadvantage in the workforce due to the child policy. ${ }^{9}$ The caretaking of two children puts a larger strain on the families, especially women, and the current concept of family internal caregiving might not be sufficient to meet the needs. Government-organized day-care-taking systems would enable the couples to maintain in the labor market and to reduce the strain on grandparents, as caretakers for their grandchildren. In Shanghai, the Municipal Commission of Health and Family Planning ${ }^{10}$ made a decision to provide a maternal leave of 128 days and paternal leave of 10 days to support families in line with the policy shift. ${ }^{11,12}$ To deal with the strains on the health care system partly due to releasing the one-child policy, the government has promised to provide an additional 89,000 maternity hospital beds and to train an extra 140,000 obstetricians and midwives. ${ }^{13}$ After over 30 years of having just one child, to shift to two children is going to change the society in remarkable ways, especially as the one-child-policy propaganda has created a norm for Chinese families to only have one child. To dream and aspire more than one child was out of consideration for most families. It means double as much caretaking is needed, double as many health care facilities for perinatal and pediatric care, but also the school system and universities have to expand their capacities to meet the new requirements of students. The rise in the population will also have an impact on the environment and architecture of the country. It is, therefore, of paramount importance to understand the needs and expectations of women, to target these requirements, and to encourage women and their families to consider getting a second child. The understanding of the families' expectations will support China to adapt quickly to the rising needs of health care and target social support to the families. This study aims to describe how women experience decision-making on their reproduction and family planning.

\section{Methods}

The study was conducted in Hangzhou during August and December 2016. The study design, a qualitative study, was set up as a thematic analysis, according to systematic text condensation (STC) of interviews conducted with Mainland Chinese Women in Shanghai and Hangzhou. Interviews were conducted with Mainland Chinese Women in Shanghai and Hangzhou. The China Child Policy Interview (Schwank S, China Child Policy Interview, Unpublished Manuscript, 2016) is a 26-item semistructured interview on women's anticipations to motherhood and questions related to the decision-making of having a second child. The interview questions focused on the impact of the child policy shift on families' mental and physical health, as well as their judgment and decision-making whether to have a second child. Emphasis is put on different aspects of decision-making with regard to the child policy shift and its impact on families. Further questions concerning psychological health, family dynamics with respect to childcare, domestic vs labor work, and financial considerations are discussed. The interview was developed by the first author and revised in collaboration with the other authors of the study and experts in semistructured interviews at Columbia University and Yale University. A pilot group of interviews were conducted as part of the training program for the master students, before conducting the actual interviews. The interviews were conducted individually with each woman after they have signed written consent and were orally informed about confidentiality, purpose of the research study, and their option to withdraw from the research project at any time. The research team had discussed the content of the interview question and its appropriateness, with several Chinese women, in PRC, Hong Kong, USA, and Sweden, prior to the study.

\section{Participants}

Women aged 18 years or older, who spoke Chinese, were invited to participate through a flyer distributed on Hangzhou Normal University Campus and through social media WeChat. Master students in Social Work and Counseling at Hangzhou Normal University recruited the participants during August and December 2016. All 37 participants $(n=37)$ in the current study were Chinese citizens. The participating women 
had an average age of 29.51 years, a bachelor's degree, and came from the urban regions of Shanghai and Hangzhou. All participants were either working or studying at the university. The majority of the women were single $(n=20)$, followed by married women $(n=16)$, and one participant who lived with her partner $(n=1)$. Half of the participants worked less than 40 hours a week and the other half more than 40 hours a week. The amount of working hours may potentially impact the decision-making of the women, which is why this variable was collected. The participants' demographic characteristics are summarized in Table 1.

\section{Data collection}

The interviewers, master students of social studies, contacted the participants through WeChat, and written informed consent was obtained from all participating candidates. Participants were informed that they could withdraw from

Table I Demographics at the time of first interview

\begin{tabular}{|c|c|}
\hline Participants & $N=37 M(S D)$ \\
\hline \multicolumn{2}{|l|}{ Gender } \\
\hline Female & 37 \\
\hline Male & 0 \\
\hline Mean age (years) & $29.5 \mathrm{I}(1 \mathrm{I} .45)(19-48)$ \\
\hline \multicolumn{2}{|l|}{ City } \\
\hline Hangzhou & 35 \\
\hline Shanghai & 2 \\
\hline \multicolumn{2}{|l|}{ Marital status } \\
\hline Married & 16 \\
\hline Relationship & 1 \\
\hline Single & 20 \\
\hline \multicolumn{2}{|l|}{ Education } \\
\hline University/College & 29 \\
\hline High school & 6 \\
\hline Mandatory education & 2 \\
\hline \multicolumn{2}{|l|}{ Hours at work (h/week) } \\
\hline$<40$ & 19 \\
\hline$=40,000$ & 4 \\
\hline$>40,000$ & 14 \\
\hline Annual income (Yuan) & $31,923.53$ (SD 49,895.2I) $(0-250,000)$ \\
\hline \multicolumn{2}{|l|}{ Number of children } \\
\hline None & 18 \\
\hline 1 & 14 \\
\hline 2 & 5 \\
\hline \multicolumn{2}{|l|}{ Sickness } \\
\hline No & 37 \\
\hline Yes & 0 \\
\hline
\end{tabular}

Notes: The official exchange rate was approximately US $\$=6.20$ Yuan; N, number of participants. the study at any time. Demographic variables, such as family background, working situation, education, annual income, presence of illness, and number of children in the family, were gathered to describe the sample. Presence of illness was included in the sample as this was considered to potentially impact the women's decision-making on whether to have a second child. Participants were asked to discuss different factors they considered impacting their decision-making: interfamily situation (family members influencing and contributing to the decision-making), potential impacts on families' decision-making as social aspects (ie, status, social bias of age), the competitiveness in school, and education. It was of interest whether families consider it to be a contributing factor to have a second child or potentially avoid having two children due to the financial and time factor to engage in tutoring and after-school activities that improve their likelihood to stand out among the other students and therewith increase the chances for better higher schools and universities. The career plans, particularly the women's; being from the one-child-policy generation and how that affects the decision-making; medical aspects (ie, age, fertility); and governmental incentives for second child (ie, parental leave, perinatal ward) were on the list of options as well.

Master students of social studies at Hangzhou Normal University conducted all interviews during August 2016 to December 2016 under the guidance of the study's first and second authors as part of their master program. The interviewers are solely data collectors. A total of 140 people have currently completed an individual interview that ranged from 30 to 90 minutes in length; in the current study, a sample of 37 interviews is presented, as the number of 37 interviews was considered sufficient to capture the phenomena of the research question. The sample of women was similar in age range, which was an additional selection criterion to consider 37 interviews. The interviews were recorded with the participants' permission, all interviewed candidates signed written informed consent, and then translated from Chinese to English by the first author and third author of the study. All original interviews and informed consent are securely stored at Hangzhou Normal University under the responsibility of the third author. The study received ethical approval from Fudan University, Public Health Department with IRB \#00002408.

\section{Data analysis}

Data collection and analysis were performed by different research team members. Each interviewer transcribed the interviews they conducted. The analysis included STC, following the four-step process described by Malterud. ${ }^{14}$ 
STC is well suited for descriptive analysis of qualitative data from interviews and offers a process of intersubjectivity, reflexivity, and feasibility, while maintaining a responsible level of methodologic thoroughness. ${ }^{15}$ In accordance with the first step of STC, the authors read the full text of all of the interviews to obtain an overview of the data and a general impression of the whole material. ${ }^{16}$ The authors independently created preliminary themes associated with judgment and decision-making on whether to have a second child. The separate themes were then discussed, merged, and adjusted. In the second step of the analysis, both authors systematically reviewed the transcripts line-by-line to identify meaning units containing information and providing knowledge about the study questions. Thus, the data were reduced to a decontextualized selection of meaning units sorted as thematic code groups. In the third step, the meaning units of the code groups were sorted into a few subgroups. ${ }^{17}$ Descriptions and concepts were developed as an analytic text, to provide credible narratives grounded in the data about the participants' experiences of whether to have a second child or not. The authors confirmed that the synthesis and quotations reflected the original context by returning to the full transcripts. The analytic text of each code group was concentrated into headings, constituting the final themes.

\section{Results}

The results are divided into main decision needs and influencing factors that contribute to the women's decision-making. The way the women answered was predominantly emphasizing more on influencing factors and needs and less on the main decisions.

The factors contributing to the decision-making can be considered as a first step toward a better understanding of what women actually need. Themes showing the contributing factors of the decision-making are presented. Areas of improvement of care and social reorganization in order to meet women's needs are emphasized.

The six themes and related subgroups emerged from the analysis: 1) status of women, 2) career, 3) benefits and challenges of two children, 4) one-child generation, 5) governmental support and incentives for second child, and 6) restrictions of reproductive freedom. These factors contribute to the women's prolonged decision-making on whether to have a second child (Table 2).

\section{Status of women}

The majority of the participants emphasized the importance to improve the status of women in the China labor force. The two-child policy puts the women's position in society to the
Table 2 Themes and subgroups

\begin{tabular}{|l|}
\hline I. Status of women \\
\hline Gender equality in society \\
Gender equality in labor force \\
Gender equality in family \\
\hline 2. Career \\
\hline Limitation in career opportunities \\
Worrying about the child's negative impact on the career \\
\hline 3. Benefits and challenges of two children \\
\hline Family balance \\
Yin and yang \\
Work/family pressure \\
Competition in school \\
\hline 4. One-child generation \\
\hline Family norm \\
Little emperor \\
\hline 5. Government support and incentives for second child \\
\hline Financial support \\
Parental leave \\
\hline 6. Restriction of reproductive freedom \\
\hline Experience the restrictions \\
Critique of governmental restrictions \\
\hline
\end{tabular}

center of attention. Women are essential for the labor market in the PRC and contribute to secure the country's economic growth. Due to the one-child policy, young employees are limited, and recruiting foreign labor is not sufficient to cover the needed workforce. Therefore, it is important to provide good work structures and incentives for women with both one and two children to remain at work. Women's status and discrimination should be actively counteracted. Structures such as parental leave, flexible working hours, possibilities to breastfeed, child care services, and good perinatal health would reduce discrimination and facilitate the women's possibilities to remain at work. The women emphasized the importance to create female- and family-friendly work environments.

Improve women's social status, as well as the employment conditions, work schedule and so on (facilitate to go home for breastfeeding and return to work afterwards). [201719]

A main concern many women described is their difficulties to remain in the labor market and yet meet the traditional role model of the family.

Improve support for women, who give birth to two children, because the second child affects women's work and family life. [201703]

This concern has been described by some women in the pragmatic approach to stay at home to look after the children, 
due to lack of public or private family support to look after the children.

I will quit my job to be a stay-at-home mom. Of course,

I can't look after my children without the help of my parents. [201730]

The importance to protect the women that get especially vulnerable in the competitive labor market, combined with the traditional role model has been addressed too.

Women should get special protection of society during the period of birth, and severely punish those men, who have been unsettled during the period of pregnancy. [201723]

\section{Career}

Women mentioned their hesitation to have a second child, which will limit their career opportunities. Employers might withhold promotions, due to concerns of rising costs. Women's ambivalence, being torn between family obligations and career opportunities, may contribute to their prolonged decision-making. The ambivalence women reported increased in severity, when having to take care of two children. The choice of a less competitive position to balance the family duties and work has been a reoccurring theme of the women in the interviews.

I choose a work, which doesn't take up too much time and

it doesn't have too much pressure. [201727]

Women are aware of the impact a second child potentially has on their career.

My career will be limited. [201729]

The issue of promotion:

Two children may delay the career, due to slower promotion or even unemployment, which lowers the women's status. [201736]

The ambivalence of traditional family roles and career opportunities:

When I happen to be in a rising career, at the time of the birth of the second child, I will lose the opportunity to be promoted. [201733]

Women are hesitant to give up their stable jobs, due to worries of losing their careers:

Because my current working environment is very stable, to conceive a second child, would disrupt the rhythm of my work now. [201734]
Due to the traditional role of the women in the family, involving many roles, employers may hesitate to employ women with two children.

I think the two-child policy will influence the professional women. The boss at work will query if the mom who has two children will put all her energy into her work. [201730]

\section{Benefits and challenges of two children}

A central aspect of the women's judgment regarding having a second child has been the families' perception of benefits and challenges, which they have taken into account in their decision-making. Children learn through the themes such as family balance, in line with a yin and yang tradition, as well as the sharing and cooperation, when siblings were present, but there were also challenges encountered while having two children, such as work and family pressure and competition in school. As one of the participants mentioned:

Positive about the two-child policy is the family relationship continuation; the home will be filled with more life.

[201739]

The yin and yang of the family is well reflected in the following participant's comment:

Two children make the family more balance and children have a company with each other. Children know how to get along with people. And it has a good effect on the children's personality and character. [201730]

The financial security for the future was another advantage of two children reoccurring often in favoring two children. Two children provide a greater security, as one of the interviewed women said:

Two children can grow up together and secure my retirement, as two children will take care of me. [201729]

Another woman emphasized the reduction of concerns during retirement, as this is primarily covered by the family rather than the state.

Your life will be more relaxed in retirement age; children would take care of you. [201727]

Challenges the families encountered with having two children were widely reflected. A recurring theme was the pressure on the family in combining work and the competition in school, a competition that increased with more children due to limited resources. The insufficient public caretaking options and within-the-family caretaking options, such as grandparents who are not able to take care 
of two children and the women taking on care-taker position, reduce their career opportunities and labor force. The women frequently mentioned the financial pressure to have with a larger family, especially in urban areas where housing is very expensive. One of the women described her family's challenge as such:

Two children generate more family expenses, for both husband and wife. The work pressure and life pressure increase. [201739]

The pressure on the families, especially women with the heavy workload and duties at home, was reflected in the women's multiple roles.

Parents will take more energy and financial resources. Especially for the mum, it takes her more time to look after her baby when her baby is born. It's a challenge for professional women. [201730]

Another aspect considered as negative, which shows the heavy propaganda of the one-child policy, is the shortage of resources.

The population increase, the shortage of resources, the burden of families, and the increased complexity of family relationships. [201737]

In China, education has a very high status and is extraordinarily competitive since imperial times, with its imperial exams. Parents dedicate their life to the education of their children, which reached an extreme during the one-child policy. Many families are, therefore, concerned about the second child, as this woman said:

The grades between two children will be compared. The children will generate some mental stress due to the constant comparison. The economic pressures is very huge. My present income and my future income, the cost of a child's birth, the cost of education in the future. [201729]

Due to the competitiveness in Chinese schools, parents spend a lot of time to further educate their children.

The stress of raising children would increase in middle age. Children will have a huge psychological pressure and there will be more pressure laying on them to achieve in school and work. Income, education, spending increase. [201727]

\section{One-child generation}

The impact of the one-child policy generation and its norm setting contributed to the women's perception of the standard Chinese family. Four grandparents, two parents, and one child have been extensively promoted to be the norm for the PRC and acting against the norm being considerably sanctioned, condemned, and associated with acting against the society's norms and values. The one-child policy has contributed to the development of a nuclear family focusing all the attention on one child, similar to the attention of the emperor, which is why the children from the one-child policy are also named "little emperors". The description of how normative the family structure had become, summarized one of the respondents, reflecting on her situation.

My uncle and aunt have only one child, to be an only child is considered the norm. However, they still are very envious of people who have siblings. As a consequence, since I was the only child, my feeling is that the family centers around me, considering me to be the emperor of the family. [201710]

This generation of "little emperors" is also considered to be more self-centered. Their thoughts and behaviors are usually focused on their own needs. As their parents and grandparents have overindulged the children, it is difficult for them to act in a socially desirable, community-centered way. Raising children themselves limits their opportunities for selffulfillment and forces them to conform to children's needs. The two-child policy contributed to women's consideration of changing family norms, as one woman commented:

How other people judge and decide on whether to have two children doesn't affect me. I think that having two kids in the future will be an advantage. It will make them share and be more considerate of their parents. [201736]

\section{Government support and incentives for second child}

The women emphasized the importance of governmental support provided to families. The responses regarding governmental support were divided into financial support for families with two children (second child allowance), including education support and parental leave that should be implemented and extended. Governmental incentives for a second child that should be provided, such as parental leave, paid maternity leave, and insurance, have been supported by many of the participants. The Shanghai Municipal Commission of Health and Family Planning has addressed this major issue for the families in line with the two-child policy. Women claimed that they now get a maternal leave and a reimbursement during their leave and fathers get a salary-paid paternal leave. This should remove some of the burden that is on the family, particularly the grandparents who are heavily 
involved in the caretaking of the grandchildren. Without the grandparents' support, the families faced with difficulties to organize the caretaking of the children, due to the lack of sufficient caretaking resources from the government, thus leading to the women's decision not to have a second child, if the grandparents are not supportive in taking on the care of their second child. According to a woman's statement, having a second child is a family decision, not uniquely a decision made by the woman. Due to the implementation of the two-child policy, many women of advanced age consider having a second child, which means that also their parents are older and may not find themselves capable to care for two children. Many women expressed the importance of maternity leave in many of their responses.

Time extended maternity leave, confinement, give the child father holiday, provide better free medical care and improve the education environment. [201734]

The government's responsibility to provide second child incentives through paid leave and allowance for second child were also reoccurring opinions of the women.

Government incentives for second births, parental leave, paid maternity leave. [201723]

An important argument for governmental parental leave was also addressed:

Both husband and wife should have parental leave, which prevents discrimination of pregnant women and provides economic subsidies. [201724]

Financial aspects have been a major concern for the women, due to rise in expenses with two children. Potential relief of the families' financial burden could be tax relief, social support, reduction of environmental pollution, governmental financial support for school costs, and an option for providing appropriate subsidies. Women thought that the younger generations considered having a second child can be a financial problem. They also imagined that the government support of elderly care services both in urban, but particularly in rural areas would be important to reduce the burden of women's multiple caretaking roles. The security of retirement is a major concern of many Chinese women, and they expressed little trust in government support of this matter as one of the participants described:

Improve the social pension system, standardize the work of old-age care services, promote the healthy development of old-age care services, and further increase governmental investments, eliminating the security risks of the major pension agencies, standardization, legalization, strengthening the rural elderly health care. Protection in place; promote enterprise community building nursery, so that women can easily maintain at work. [201710]

Besides the financial support of the government to raise a two-child family, the women raised the importance of an improved school system as a major issue of concern.

The improvement of the education system is much more important than the hard core education received from an early age. There is hope that children will be able to receive free education and enjoy a life they are interested in and develop their specialties. [201710]

Moving away from the overly competitive elitist system toward a more balanced system, providing more equal opportunities, was one of the suggestions the women expressed.

We hope that children's early education can get balance the distribution of resources, and get some help from the government. [201724]

\section{Restriction to reproductive freedom}

The participating women answered openly to the question with regard to the governmental restrictions on the reproductive freedom in the PRC, as cause of the specific child policy in China. The responses were in accordance with the child policy, but also critical answers were provided, which was counterintuitive and not expected. Many participants described their experience of the restrictions, fees, and incentives for single-child families during the one-child policy.

I think that for women, the government's birth control policy cannot be decisive to restrain the number of children a woman wants to give birth to. We have no obligation to let others decide how they want to live. [201734]

Very clear opinions against the limitation of the reproductive freedom were addressed.

The child policy is not in accordance with humanitarian rights. [201723]

Other women showed a certain hesitation of openly sharing their opinion.

The restriction should not be mandatory, but be based on the actual situation of the individual. [201724]

A third group of women answered in line with the onechild policy propaganda of its need to restrict the population overflow.

The government policy matches the national population.

Support the government's decision. [201721] 
Some women considered it to be a necessity to restrict the reproductive freedom.

I think this is necessary that there is a limit in the number of children to be raised and that more families will give birth to children without any scruples; based on the idea of having a boy. There is an issue that children will not get good care after childbearing. That is great harm to the children. [201710]

\section{Discussion}

This study aimed to describe the Mainland Chinese women's decision-making on their reproduction and family planning. The results captured how the two-child policy is impacting women's decision of getting pregnant again. The most important results of the study were the impact of gender inequality especially when having a second child. The women emphasized the conflict of being a modern professional woman in a city and the traditional family values and expectations.

We found that women's status in a society plays an important role. The issue of gender inequality and access to health care was a concern for the women when making their decisions about their reproductive life. ${ }^{18,19}$ The family-work conflict has been shown to be more predominant in women with more than one child, as shown in a study by Yang. ${ }^{20}$ Women bearing children less than 3 years old are forced to interrupt work, due to a lack of public child care services. It is important to increase public child-care services in line with balancing work and family. ${ }^{20}$

The implementation of the two-child policy may cause some potential risk for women's employment and career development, ${ }^{21}$ which makes them less likely to conceive a second child. There is a clash of values between the traditional family-centered duties of a woman in the domestic caretaking vs the career and financial security a woman's labor job provides. Women have many social roles; on the one hand, she will have to educate and take care of the children and the parents, and, on the other hand, she has to reinforce her social status. The two-child policy increases women's family responsibilities and undermines women's social roles. Work environmental factors such as glass ceiling effect, glass cliff, and blind passing ${ }^{22}$ may contribute to women interrupting their career, using the two-child policy as an excuse to escape gender inequity at work. ${ }^{19}$

In line with women's dilemma of having a child or focus on the individual career, our results have shown that women expect the government to provide parental leave for families, who consider having a second child. To improve social gender equity and encourage birth, many countries have implemented a balanced policy relating to work and family, including parental leave, maternal leave with salary, trying to develop more child-care agencies, and encourage the working places to provide flexible work arrangements. These policies can effectively relieve the conflict between family and work. ${ }^{21}$ Women considered the government support to be essential to support them financially, in order to balance the decision in favor of the advantages of having a second child. Women saw this action of the government at the same time as an increase of the women's status in society and support their career. In China, family is considered the smallest significant unit. An individual is defined by the relationship between family, relatives, community, and nation at large. Hwang $^{23,24}$ described that in relationship-oriented societies such as in China, individuals must consider their reputation carefully and maintain harmony at the interpersonal level, which is related to personal and family well-being. This emphasizes the significance of family members such as grandparents on the decision-making of whether a couple should have a second child. It may bring honor to the family, but at the same time responsibility for the grandparents to look after a second child. The ambivalence whether to have a second child or not has been a recurring pattern throughout the interviews. The one-child policy has developed a generation of only children, a peculiar family structure, centering around the one child, who has been the "little emperor" of the family. ${ }^{1}$ This generation of young adults are more selfcentered and rather reluctant to have children of their own, due to the limitation of children on their own self-fulfillment. This personality style impacts the plan and decision-making on whether to have a child or not. ${ }^{25}$ In the families that wish for more balance in the family, having two children is one of the driving sources of a second child.

The restrictions to the reproductive freedom have been addressed by the women as an undecided experience of understanding of the limited resources and the impact of population growth. The women described at the same time a melancholic undertone of challenging the ancient Chinese family traditions, as well as uttered clear criticisms toward the policy. The core issues for China's population policy, which the women discussed in the interviews, are not the number of children a family should have, but the lack of recognition or respect for fertility freedom, which unfortunately remains in the new two-child policy. ${ }^{11}$ The women mentioned the biased treatment of different social groups, rural vs urban population, with regard to whether they were permitted to have a second child, prior to January 2015 when the two-child policy came into effect. Especially forced abortions and sterilizations to meet the quota of the province were conducted more in rural 
areas. ${ }^{26}$ The negative impact was that the two-child policy become a concerning issue in the Chinese society. In the 2017 Chinese national civil service job list, 13\% of the job postings specified "men only", "men preferred", or "suitable for men", ${ }^{27}$ considering women less employable, due to their multiple roles. An option to reduce the burden of women's multiple roles is to implement future practice of elderly care provided by governmental institutions, in order for women to be able to focus on their children and career. This would be in line with the United Nation Convention on Elimination of Discrimination against Women. ${ }^{28}$ With the two-child policy, the issue remains that couples are prohibited to decide the number of children they wish to have, and such restriction on reproduction is not the "highest attainable standard" of mental health. ${ }^{29}$ The role of the fathers should also be more inclusive in order to share the care taking of the children. The government support of fathers' leave would be an option to achieve that, as the trial in Shanghai. Fathers receive 10 days leave and mothers 128 days. ${ }^{30}$ The study demonstrated the need to continue understanding the impact of the child policy shift for families and the society of the PRC on multiple levels. Due to the primary center of the Chinese society around the family, the child policy shift impacts all areas of society and has both short- and long-term consequences on sociocultural, political, public health, perinatal health, educational, as well as labor market impacts. Welfare analysis is important when analyzing population policies. ${ }^{31}$ China's economic success has delivered tremendous benefits to its residence. But one benefit yet to be achieved, essential to China's sustainable future, is the expansion of freedom to enable each individual's life path and reproductive freedom to be pursued without state compulsion. ${ }^{32}$ With the outcomes of research on the women's judgment and decision-making with regard to a second child, support can be targeted where it is needed the most. This is of value to the governmental planning and resource allocation in health, educational, as well as environmental and urban construction.

The study provides new knowledge of factors contributing to women to postpone their opportunity to have a second child. Essential outcomes are the emphasis on gender equality, career, and governmental support in the form of parental leave and daycare to enable working women to maintain their career. These outcomes are of importance to further develop and improve the two-child policy, making it more attractive for families of urban professionals and prevent it from becoming a trap for women's career. Diminishing their career opportunities will have a negative impact on the highly qualified labor force that is so essential for China's economic growth. ${ }^{33}$ The women's decision-making on whether to have a second child is essential, as women contribute some $41 \%$ to China's GDP. ${ }^{34}$

\section{Methodologic considerations}

The limitation of the study is the focus on urban areas of Shanghai and Hangzhou and therefore the sample being skewed toward well-educated women. With an average age of 29.51 years and a majority of women not yet having a child, the decision-making process cannot represent the general population's decision-making. Rural areas have not been included in the present study, or an older generation. Therefore, the transferability of the findings should be considered with caution. The research participants did not include people from Hong Kong, Macau, or Taiwan, where the reproduction control is different from the one in the PRC. A potential limitation of the study is the population being well-educated Chinese women from urban cities and not taking rural areas into consideration. This can, however, also be considered as a strength of the study, providing generalizability of the outcomes to other urban areas in China, where women are facing similar situations. The study is unique and been conducted shortly after the release of the two-child policy, capturing the decision-making on getting pregnant with a second child, career and family choices, questions, and concerns of women in that time of a major societal shift.

Credibility in this study has been attained through thorough descriptions of the different steps of the research procedure, from recruitment procedure to data analysis. STC is recommended by Malterud, ${ }^{14}$ as it is a method that provides a process that is easy to follow, communicate, and supervise, from preliminary themes to final categories, including the use of quotes, to ensure credibility. STC allowed for collaboration between authors and supervisors as a way of validating the data analysis and the emerging themes. The authors independently read the interview transcripts and later discussed and merged themes to form final themes and subgroups, in order to attain dependability. Continuous discussions and dialog between authors were done to ensure the results and conclusions of the study to be grounded in the empirical data.

The one-child policy and its enforced restrictions to reproductive freedom have been controversially addressed in western research, ${ }^{11}$ the United Nations, ${ }^{9}$ and societies. The child-policy shift and the analysis of its consequences on women's decision-making of having a second child was a "hot topic". To gain as unbiased and as limited politically correct answers from the interviewed women as possible, Chinese research team members conducted all the interviews and they had been trained by the project leaders prior to the interviews to be aware of personal biases. 


\section{Acknowledgments}

The study was supported by the Chinese American Psychoanalytic Alliance (CAPA) and the Swedish Foundation for international Cooperation in Research and Higher Education, STINT (IB2016-6905).

\section{Disclosure}

The authors report no conflicts of interest in this work.

\section{References}

1. Cameron L, Erkal N, Gangadharan L, Meng X. Little emperors: behavioral impacts of China's one-child policy. Science. 2013;339(6122): 953-957.

2. Consultative Conference: "The government must end the one-child rule." AsiaNews.it, May 16, 2007. Available from: www.asianews.it/ index.php?1=en\&art=8757\&size=A. Accessed September 28, 2018

3. Zhao YT. The impact of the family planning policy on family structure. Reading Digest. 2016;20(5):114.

4. Ni H, Rossignol AM. Maternal deaths among women with pregnancies outside of family planning in Sichuan, China. Epidemiology. 1994; 5(5):490-494.

5. Doherty JP, Norton EC, Veney JE. China's one-child policy: the economic choices and consequences faced by pregnant women. Soc Sci Med. 2001;52(5):745-761.

6. Chun-Yi G, Lingling L, Yan D, Xinli Z, Shuchang X, Xiuhong W. Job analysis and needs assessment of advanced midwifery practitioners in the hospital. Chin J Hosp Adm. 2016;32(50):534-538.

7. Gu C, Wu X, Ding Y, Zhu X, Zhang Z. The effectiveness of a Chinese midwives' antenatal clinic service on childbirth outcomes for primipare: a randomised controlled trial. Int J Nurs Stud. 2013; 50(12):1689-1697.

8. Gu C, Zhang Z, Ding Y. Chinese midwives' experience of providing continuity of care to labouring women. Midwifery. 2011;27(2):243-249.

9. United Nations. Case studies in population policy: China. Department of International Economic and Social Affairs. 1988. Available from: http://www.wsjsw.gov.cn/wsj/. Accessed October 10, 2018.

10. Shanghai Municipal Commission of Health and Family Planning Institute; 2017. Available from: http://www.wsjsw.gov.cn/wsj/. Accessed September 28, 2018

11. The two-child policy in China: what to expect? Lancet. 2013; 382(9907):1758. For Wang Pei'an's answers to reporters' questions on the two-child policy, see http://www.nhfpc.gov.cn/zhuzhan/ zcjd/201311/24fb42100d9945a99d e21712f3f38f55.shtml

12. Rui Z. Second-child policy increases births by 7.9 percent. China Daily; 2017. Available from: http://english.cctv.com/2017/01/23/ARTIFwPQopWHXOK1Z30ytmAg170123.shtml. Accessed September 28, 2018.

13. The Lancet. What to expect for China's health in the future. Lancet. 2017;389(10066):226. For China's 13th 5-year plan on health care, see http://english.cctv.com/2017/01/11/ARTIuVEf5LNEyNvuBefnmLNP170111.shtml. Accessed October 10, 2018.

14. Malterud K. Systematic text condensation: a strategy for qualitative analysis. Scand J Public Health. 2012;40(8):795-805.
15. Patton MQ. Qualitative Research and Evaluation Methods. 3rd ed. Thousand Oaks, CA: Sage; 2000.

16. Graneheim UH, Lundman B. Qualitative content analysis in nursing research: concepts, procedures and measures to achieve trustworthiness. Nurse Educ Today. 2004;24(2):105-112.

17. Polit DF, Beck CT. Essentials of Nursing Research: Appraising Evidence For Nursing Practice. Philadelphia, PA: Wolters Kluwer; 2017.

18. Wang J, Ding Y, Cy G, Bao LP. Influence research of two-child policy on healthcare industry in Shanghai. China Hosp Manage. 2015;35(8):5-7.

19. United Nations. China Gender Fund for Research and Advocacy; 2017. Available from: http://www.unwomen.org/en/get-involved/step-it-up. Accessed September 28, 2018.

20. Yang H, Lyu Y, Ren L. A study on the impact of bearing two children on urban youth's work-family balance: the empirical analysis based on the third survey of chinese women's social status. Population \& Econ. 2016;2:1-9.

21 . Wu F. The risk of women's development and policy of family support after China's two-child policy. Acad J Xian Jiaotong Univ. 2016: $128-130$.

22. Xiao Q, Tong L, Zhang Y, Sun Y. Women's career security under the comprehensive two-child policy. J Henan Univ Sci Technol. 2016;34: 92-98.

23. Hwang K-Kuo. Face and favor: the Chinese power game. Am J Sociol. 1987;92(4):944-974.

24. Hwang K-K. Foundations of Chinese Psychology: Confucian Social Relations, Vol. 1. New York, NY: Springer; 2011.

25. Li J. China' Family Planning Program: How, and How Well, Did It Work? Research Division Working Papers, 65. New York: Population Council; 1994.

26. Li Y. Reflections on the causes of forced abortion in China. Lancet. 2012;380(9844):804.

27. Human Rights Watch. Available from: https://www.hrw.org/ news/2018/04/23/china-job-ads-discriminate-against-women. Accessed September 28, 2018.

28. United Nations, Human Rights. Convention on the Elimination of All Forms of Discrimination against Women. Available from: http://www. ohchr.org/EN/ProfessionalInterest/Pages/CEDAW.aspx

29. United Nations, Human Rights. International Covenant on Economic, Social and Cultural Rights. Available from: http://www.ohchr.org/EN/ ProfessionalInterest/Pages/CESCR.aspx 25.04.2018

30. Covington \& Burling LLP, International Law Firm. Changes to Chinese Parental Leave Benefits. International Employment. 2016.

31. Liao P-J. The one-child policy: a macroeconomic analysis. J Dev Econ. 2013;101:49-62.

32. The end of the one-child policy in China? For two-child policy discussion in the annual plenary sessions of Chinese People's Political Consultative Conference and the National People's Congress. The Lancet. 2011;377. Available from: http://english.peopledaily.com. cn/90001/90776/90882/ 7310975.html. Accessed October 02, 2018.

33. World Economic Forum; 2018. Available from: https://www.weforum. org/agenda/2018/04/women-in-china-contribute-more-to-gdp-than-inthe-us-viewing-them-as-leftover-is-problematic/. Accessed July 11, 2018.

34. Cai Y. 2018. Available from: https://www.yicaiglobal.com/news/ chinese-women-contribute-more-gdp-overseas-counterparts 11.07.18
International Journal of Women's Health

\section{Publish your work in this journal}

The International Journal of Women's Health is an international, peerreviewed open-access journal publishing original research, reports, editorials, reviews and commentaries on all aspects of women's healthcare including gynecology, obstetrics, and breast cancer. The manuscript management system is completely online and includes

\section{Dovepress}

a very quick and fair peer-review system, which is all easy to use Visit http://www.dovepress.com/testimonials.php to read real quotes from published authors. 